\title{
Unsaturated volcanic tephra and its effect for soil movement in EI Salvador
}

\author{
José Alexander Chávez Hernández ${ }_{5}^{1,2, *}$, Jiři Šebesta ${ }^{3}$, Lubomir Kopecky ${ }^{4}$, \\ Reynaldo López Landaverde ${ }^{5}$, José Landaverde ${ }^{6}$ \\ ${ }^{1}$ Department of Geotechnics, Faculty of Civil Engineering, Czech Technical University in Prague, ČVUT, Prague, Czech Republic \\ ${ }^{2}$ Unidad Ambiental, Oficina de Planificación del Área Metropolitana de San Salvador, OPAMSS, San Salvador, El Salvador \\ ${ }^{3}$ Czech Geological Survey, Prague, Czech Republic \\ ${ }^{4}$ Department of Mechanics, Faculty of Civil Engineering, ČVUT, Prague, Czech Republic \\ ${ }^{5}$ Departamento de Recursos Naturales y Medio Ambiente, Facultad de Ciencias Agronómicas, Universidad de El Salvador, San Salvador, \\ El Salvador \\ ${ }^{6}$ Departamento de Geotecnia, Escuela de Civil, Facultad de Ingeniería y Arquitectura, Universidad de El Salvador, San Salvador, El \\ Salvador
}

\section{Email address: \\ jose.alexander.chavez.hernandez@fssv.cvut.cz (J. Chavez), jiri.sebesta@geology.cz (J. Šebesta), kopecky@fsv.cvut.cz (L. Kopecky), agrorey@yahoo.es (R. Lopez),jmlq30@yahoo.com.mx (J. Landaverde)}

\section{To cite this article:}

José Alexander Chávez Hernández, Jiři Šebesta, Lubomir Kopecky, Reynaldo López Landaverde, José Landaverde. Unsaturated Volcanic Tephra and Its Effect for Soil Movement in El Salvador, Earth Science. Vol. 2, No. 2, 2013, pp.58-65. doi: 10.11648/j.earth.20130202.15

\begin{abstract}
In El Salvador during the rainy season or when major earthquakes affect the area, processes like mass movements, liquefaction, erosion and floods affect the territory leaving environmental, social and economic damages. The volcanic tephras called "Tierra Blanca Joven" (TBJ) which is a product of the last plinian eruption of the Ilopango Caldera are the more problematic region in the Metropolitan Area of San Salvador. In El Salvador during the summer and rainy season the groundwater level remains low in most of the areas, this means that the soils in the country are unsaturated and there are capillary forces that act on the soil structure making that an "apparent cohesion" (suction) improve the strength of the soil; this circumstance makes that the slopes are almost vertical and temporally stable, but will collapse when wetted or during seismic events. To that problematic is possible to add that the majority of the water pipelines are in bad condition and when they fail is possible to expect the collapse of entire streets or houses. Wetting of the soil is likely to occur following construction development, because evaporation is reduced by covering the ground surface with a structure. For unsaturated soils the use of two independent stress variables: net stress and suction are needed. Suction values of TBJ "G" unit of the proximal facie were obtained using pressure plate, tensiometer and filter paper to obtain a Soil-Water Retention Curve (SWRC); the use of this curve into finite elements software can help to obtain the shear strength and permeability properties. For monitoring, the use of Quickdraw tensiometers (suction) and TMS3 (soil moisture content) is proposed, because it could be a way to build a field methodology for early warning system for the slopes for urban planning and risk assessment.
\end{abstract}

Keywords: Tierra Blanca Joven, Erosion, Mass Movement, Unsaturated, Suction, Tensiometer, Soil Moisture Sensor

\section{Introduction}

Central America is located along the Ring of Fire where the subduction process causes high volcanic activity, as well as intense earthquake activity. In addition it's an area that is located between the Pacific and Atlantic Oceans, where hurricanes affect constantly El Salvador and other neighboring countries. The Metropolitan Area of San Salvador (MASS) grew without a clear urban planning and problematic areas are occupied nowadays. Most of the people with fragile economic resources live in risky areas (edge or inside the ravines, close to scarps, etc.) increasing the vulnerability to natural hazards.

The MASS stratigraphy consists mainly of the San Salvador formation, product [1,2] of the late Pliocene-Quaternary Central American Volcanic Front volcanoes. The more important strata are: the tephras TB4, TB3, TB2 (between them exist paleosoils) and Tierra Blanca Joven (TBJ) which are eruptive products of the Ilopango Caldera; also strata from the San Salvador stratovolcano like 
G1, G2 including different lava flows and ash falls are included. The location of the tuffs was controlled depending on the direction of the winds, the erosion processes and explosive force during the eruption. The basement of the area is composed [1] by the products of calderas and volcanoes of the Cuscatlán formation and remnants of andesite stratovolcanoes of the Balsamo formation.

Important areas of weathering in the MASS belong to the laterites [1] associated to the rocks of the Balsamo formation, especially atop rocks of the older Panchimalco stratovolcano which are covered by the younger tephras.

The more problematic region, because of mass wasting processes (Fig.1), is located on the extent and thick deposits of the volcanic tuffs called Tierra Blanca Joven (TBJ) which is an unconsolidated product of the last plinian eruption of the Ilopango Caldera [2]. Several authors [2-8] have dealt with the hazards, current geological and geotechnical knowledge in the MASS, focusing mainly in the Tierra Blanca Joven tephras (TBJ) (unsaturated material); indicating the decrease of strength, and collapsibility of TBJ when saturation reduces the suction and cementation.

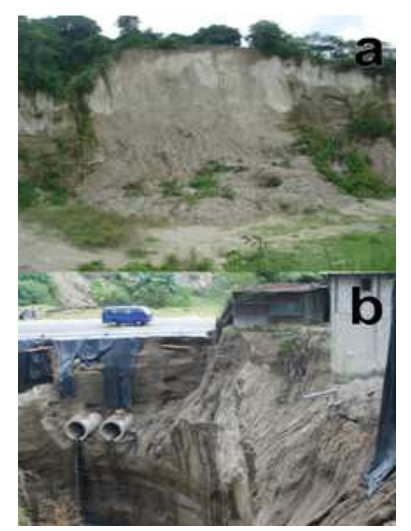

Figure 1. Mass wasting problems in Tierra Blanca Joven (TBJ). a) corresponds to las Cañas River where mass movements, erosion and collapse occur all the year. b) Is a 2005 photo of a stream in Ilopango, the landfill and pipelines of the road failed during heavy rains of hurricane Stan.

Reference [9] says that in many parts of the world soils are classified as "problematic" because of the difficulties that occur before and after the construction of foundations or roads, as well as on slopes because excessive deformation occur, which may produce undesirable swelling, settlement or collapse. Similar problems can occur in landfills, and so these soils must be identified before planning to build on them. In the early 70's and 80's it was reported the lost of billions of dollars in damage to homes, buildings, roads, etc. in the United States and this type of soil was called the "hidden disaster" [10].

In El Salvador during the two distinct seasons of the year (summer and rainy season) the groundwater level remains more than $35 \mathrm{~m}$ deep in most urban areas [5], this means that most of the soils in the country are unsaturated and there are capillary forces that act on the soil structure making that an "apparent cohesion" (suction) improve the strength of the soil, which results in greater inter-particle friction increasing the soil strength. Wetting of the soil is likely to take place following construction development, because evaporation is reduced by covering the ground surface with a structure and the failure of water pipelines [11].

The range of moisture content in TBJ was summarized by [3-4, 6-7] going from 11-36.7\% and the saturation between 39.9-82.5\%. During the present work (dry season) values of moisture of $2 \%$ were reported as well. Also during the 2012 rainy season, two small surface flows (moisture content of $32 \%$ ) occurred in monitored slopes of TBJ. Infiltration results [12] of TBJ in the study area, using the double-ring infiltrometer fluctuate between $15-7 \mathrm{~mm} / \mathrm{h}$.

Because of its young age [2] TBJ is not affected by intense weathering. However is possible to observe oxidation traces (iron oxides), which mark the areas of the water preferred pathway in TBJ.

\subsection{Properties of Tierra Blanca Joven (TBJ)}

According to [4], the TBJ units are an intercalation of layers of falls, surges, pyroclastic flows and episodes of wet (phreatomagmatic) and dry eruptions; and are identified by the letters: Ao, A, B, C, D, E, ignimbrites (Alpha and Beta), $\mathrm{F}$ and $\mathrm{G}$ from the base to the most superficial.

Sandy-silt or silty sand are the most common classification of TBJ (Fig. 2), and is possible to observe in the field that the rigidity or softness of the layers depends of the distance (facie), type of deposit and deposition, for example the pyroclastic flows are more consistent than the falls (probably because when they were deposited the temperature was not elevated), but they're not welded too much.

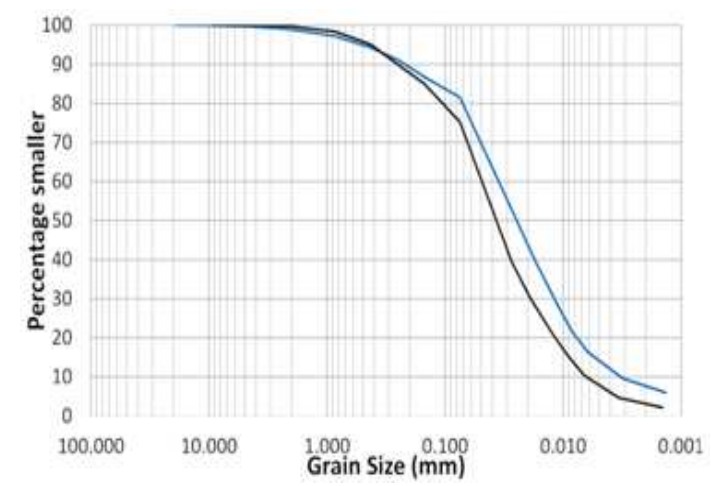

Figure 2. Grain size curve range of the TBJ fall deposit, unit G (Communication of $O$. Ayala., 2013).

The pyroclastic flows filled the paleovalleys, also the thickness and quantity of layers of that type of deposits are variable; there is presence of lithic pieces (large pieces are present in the proximal facie), pumice presence is important also and volcanic ash is the matrix.

There is presence of important areas of badlands in TBJ (zones of intense erosion with high density of drainage); where mass movements, underground erosion, sheet run off, rill and gully erosion are common. A current problem in the MASS is the urbanization of the badland areas where landfills (usually for housing projects) is a normal procedure [2]. During the past earthquakes, settlements and collapse were 
observed in the landfill areas of TBJ.

Studies made in [2] of the units D, F and G of TBJ into the environmental scanning electron microscope (ESEM) show that there are voids (where water can enter and capillary forces can develop); and the big size grains are covered by smaller ones. According to the results of the quantitative data of the ESEM most of the material is composed of silica rich volcanic glass, feldspar and small amount of clay (Communication of J. Lexa, 2012).

Of all the samples assessed with the ESEM, RTG analyses were made in the clay fraction (Fig. 2). Composition of clay mineral fraction is identical for all samples and the main alteration mineral is $\mathrm{Al}-\mathrm{Mg}$ smectite without significant participation of Fe. Minor alteration minerals represent mordenite (zeolite) and poorly crystalline mineral of the kaolinite group; both of these minor minerals are in the fraction bellow 2 micrometers. Beside alteration minerals there is present plagioclase and quartz and minor amount of illite that may represent admixture from altered rocks in the volcanic explosion center (Communication of J. Lexa, 2011).

According to [3] the small quantity of smectite (montmorillonite) found in TBJ could act as a cementing agent. However in [4] it was concluded that the cementation of TBJ, is produced by secondary mineralization; in the D unit is composed of sulfates and silicates. The mechanism of formation of this mineralization occur when the sun heat the external part of the slope, there's evaporation of the water in the soil; the vapor transport outside ions and cations from the pyroclastic deposits. Crystals forms from this chemical reactions (at atmospheric pressure and environmental temperature) forming a few millimeter thickness crust. In TBJ slopes exposed to natural environmental, this crust covers the surface, showing cementation and some protection against erosion and preventing the escape of moisture from the slope.

The presence of clay minerals in TBJ agree with the behavior of collapsible soils [13-14] which are soils composed by silts and fine sand sized particles with small amounts of clays and have low density, but are relative stiff and strong in their natural state. The cementation of the collapsible soils could consists of dried clay, salts, oxides, interparticle forces in clayey soils and chemical precipitates, which may have been added after deposition. The compacted soils can be collapsible also because during compaction a combination of soil, air and water is created.

The results for the collapse index for [6] range between moderate and severe (moisture content of 13.3\%-20.1\%; proximal facie: unit G); for [7] between moderate and lightly, (moisture content were 26.7\%-36.7\%; intermediate Facie: unit $\mathrm{G})$. Those results mean that a loss of volume happens instantly when the soil is saturated and loaded with $200 \mathrm{kPa}$. Soils that deform contractively reduce their pore space. The failure of these soils may result in a rapid evolution to a flow [15] that could travel some distance.

According to [5] the additional strength of the intact material may arise from cementation at inter-particle contacts.
The volume losses upon saturation occur suddenly and could cause the large number of mass movements during the heavy storms in El Salvador.

\section{Methods and Results}

For unsaturated soils the combination of total stress $\sigma$, pore water pressure uw, pore air pressure ua and degree of saturation are needed. For characterizing [10], the use of two independent stress variables: net stress $\sigma$-ua and matric suction ua-uw are usually used. This brings out the necessity of researching about the behavior and constitutive modeling using the critical state and unsaturated soil mechanics; to avoid scatter of results reported in TBJ samples [8] and have consistency into a more coherent framework.

Total suction [16] is comprised by two components: matric suction and osmotic suction, both give an apparent cohesion to any soil mass. The matric suction is related to moisture changes, but the osmotic suction is influenced by the salt content difference between the external water and the water inside the soil. If no additional salts are added into the soil [16] then only matric suction is needed for geotechnical problems. More research is needed about the secondary mineralization explained by [4] because at the moment is not recognized its importance in the soil mass; according to its influence it might be necessary to include the osmotic suction as an independent stress state variable in the analysis of TBJ, but also the cementation mentioned before can have some influence in the behavior.

At the moment there is no information of osmotic suction research in TBJ; only [3] measured the total suction in TBJ samples.

According to [17], the soil-water retention curve (SWRC) is an important constitutive relationship for unsaturated soil mechanics. The SWRC relates the water content of a soil to matric suction (Fig. 3a) and can be represented using the degree of saturation, gravimetric or volumetric water content. It has a similar role as the consolidation curve in saturated soil mechanics. There are three stages [18] in the SWRC (Fig. 3b): 1) the capillary saturation zone, where the pore water is in tension but the soil remains saturated due to capillary forces; 2) desaturation zone, where the water within the pores are replaced by air, this area ends at the residual water content, $\theta$ r, where pore water becomes immobile within the soil matrix and the increase of suction do not change the water content; 3 ) zone of residual saturation, where the water is strongly held to the soil and only there's moisture movement as a vapor flow.

While obtaining the SWRC in unsaturated soils [16] hysteresis was observed (Fig. 3b), depending if the soil is drying (desorption) or wetting (adsorption). This means that is necessary to choose what process is going to be simulated in order to obtain the soil property functions.

For unsaturated soils, engineering properties like shear strength, volume change and coefficient of permeability are predicted with the soil-water retention curve (SWRC) and properties of the saturated soil. These procedures although 
approximate [16] are generally adequate and practical for design in unsaturated soils.
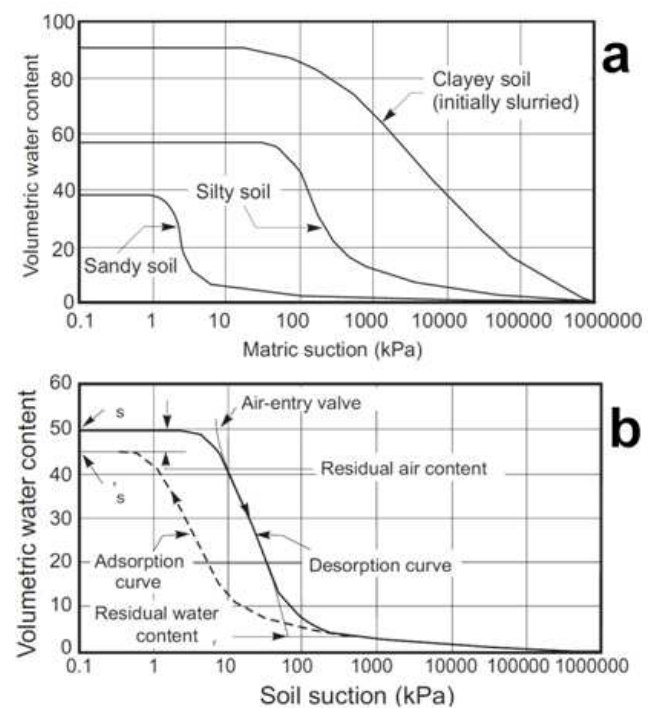

Figure 3. (a) Typical Soil Water Retention Curves (SWRC) according to the soil type; (b) different stages and important concepts of the SWRC [19].

According to [16] estimation models for water permeability (using SWRC), are divided into: empirical, statistical, correlation and regression models. The empirical model (e.g. Brooks and Corey, 1964) determines a pore-size distribution index and uses the computed index, for the estimation of the water permeability function. The statistical model (e.g. Childs and Collis-George, 1950; Burdine, 1953; Mualem, 1976; Fredlund et al., 1994) consists of a physical model of the assemblage of pore channels through which water can flow, using an integration procedure along the SWRC starting from the saturated state. Correlation models (e.g. Leong and Rahardjo, 1997) recognize an apparent correlation (using an additional soil parameter) to relate SWRC and permeability. In the regression models (e.g. Gardner, 1958) is necessary to have values of coefficient of permeability (from laboratory data or estimated, using models), then using a regression or best-fit analysis the information is introduced to obtain an equation that represents the permeability function.

For estimation of shear strength using SWRC the reference [16] also list some equations (Fig. 4) where air-entry value of the soil and the residual suction are essential. Some of the equations use the normalization and the shape of the SWRC, also the SWRC is used to control the secant slope between soil suction and shear strength.

Comparisons made by [16] between models and real soil data, revealed that the Goh et al. and Fredlund et al. equations give close estimations especially in the intermediate-high suction range; in the intermediate suction range the estimate of the peak shear strength is also reasonable.

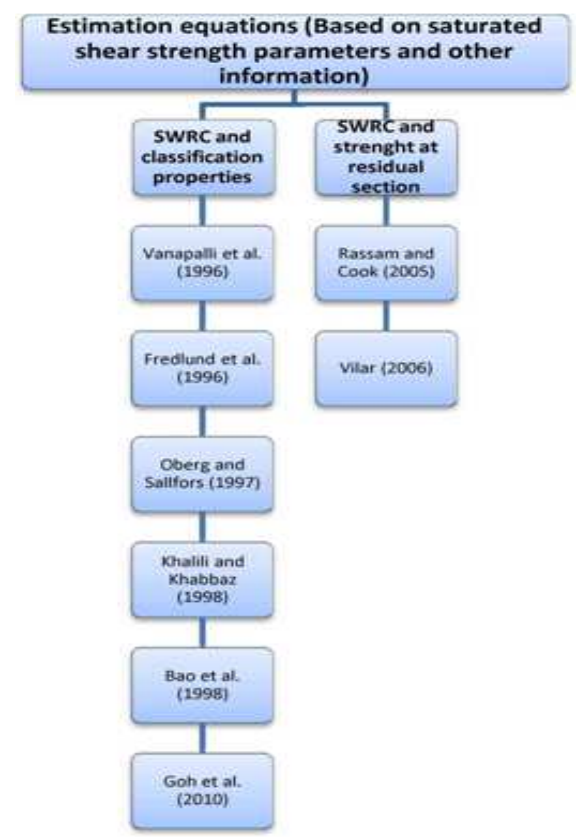

Figure 4. Estimation equations of shear strength for unsaturated soils (Modified from [16]).

Suction values of remolded samples of TBJ "G" fall unit of the proximal facie $\left(13^{\circ} 43^{\prime} 5.83^{\prime \prime} \mathrm{N}, 89^{\circ} 9^{\prime} 33.24^{\prime \prime} \mathrm{W}\right)$ were obtained in the laboratory using pressure plate and filter paper, reaching a suction value of approximately 20,000 $\mathrm{kPa}$ (Fig. 5). These values were compared to other author's results $[4-5,20]$ who concluded that the negative pore pressure (suction), weak interparticle bonding or cementation have a contribution to the shear strength.

According to [21-22] different models to describe the soil water retention characteristics are available and have been evaluated (e. g. Van Genuchten, 1980; Brooks and Corey, 1964; Kosugi, 1996; Durner, 1994; Seki, 2007). However, is important to obtain the unknown parameters on the base of known experimental data (Suction vs. water content).

To obtain the SWRC of the different models the program SWRC Fit [22] was used; it can be executed directly from the web page (http://purl.org/net/swre/). This program was developed to perform the nonlinear fitting of the soil water retention curve, where no explicit input of the initial estimate is required.

In Fig. 6 is presented the results of the SWRC (combined data of filter paper and pressure plate), using the mathematical models mentioned before. The Van Genuchten model (1980) historically has been widely adopted because of a higher degree of fitting to data from a variety of soil types; the model parameters have physical meaning [18]. According to [22] the models of Brooks and Corey (1964), Van Genuchten (1980) and Kosugi (1996) (which are unimodal pore size distribution models) can represent many SWRC of soils with a homogeneous pore structure; but in soils with a heterogeneous distribution of pore size, these models do not represent the measured soil water retention curve very well and models like Durner (1964) and Seki 
(2007) can be used.

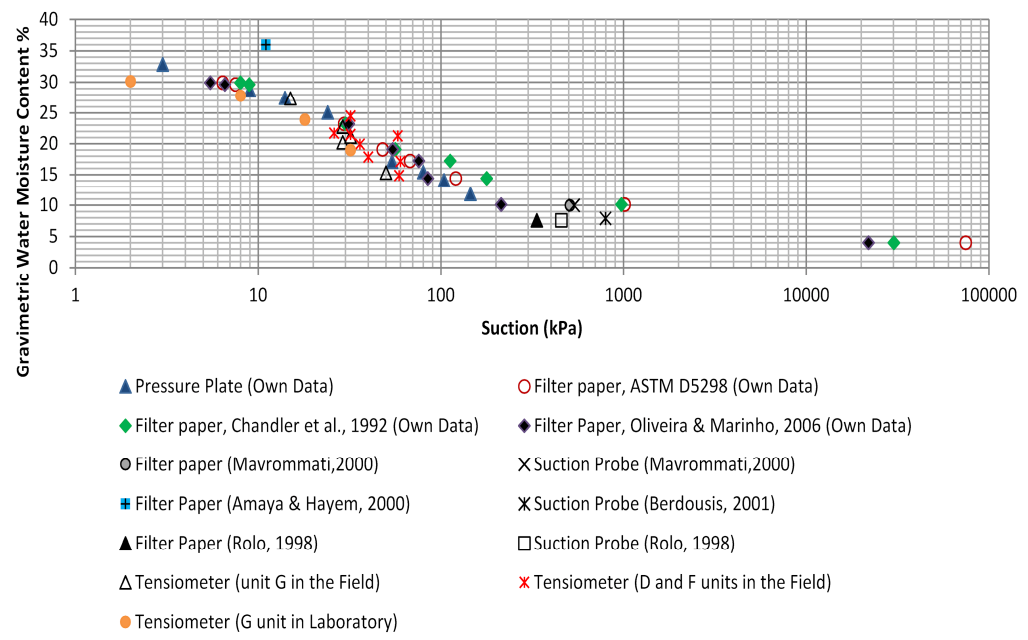

Figure 5. Results of pressure plate and filter paper tests made in a fall deposit of Unit "G" of TBJ.

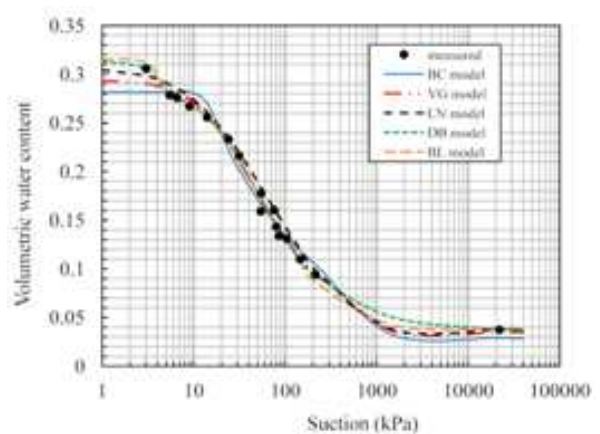

Figure 6. Soil Water Retention Curve (SWRC) build with different models, combined data of filter paper and pressure plate. BC: Brooks \& Corey (1964), $R 2=0.97796 ; V G$ : Van Genuchten (1980), $R 2=0.99093 ; L N$ : Kosugi (1996), $R 2=0.99190 ;$ DB: Durner (1994), $R 2=0.99517 ; B L:$ Seki (2007), $R 2=0.99388$.

Additionally results using the Quickdraw tensiometer in units D, G and F of TBJ are presented in Fig. 5. The proper study in the lab and field, into the framework of unsaturated soils mechanics, will help to understand the connection between the moisture quantity and behavior of the tephras. The use of soil-water retention curves (SWRC) into finite elements software will assist in obtaining the shear strength and permeability properties [10,14,16-17,23-24].

The Plaxis software uses the SWRC to describe hydraulic parameters (e.g. Van Genuchten, 1980) of the groundwater flow in unsaturated zones (Comunication of Plaxis, 2012); also is possible to choose the advance mode in the calculation mode, where the effective degree of saturation depends on the suction (SWRC) producing different results if compared with the classical mode (Terzaghi's stress).

Soilvision software also takes into consideration the unsaturated properties of the soil (SVSlope; SVFlux) and has methods of estimating the SWRC (if no experimental data of all the range is available), unsaturated hydraulic soil properties and assessing unsaturated shear strength; in addition it can simulate the relationship between precipitation, potential evaporation and actual evaporation into slope stability.
Geoslope software (SEEP/W; SLOPE/W; VADOSE/W) takes into consideration (Communication of Geoslope International Ltd, 2012) the unsaturated soil properties by using the volumetric water content (storage) function, which is the SWRC. The software present four methods available to develop the SWRC (if no experimental data of all the range is available), the first one is to estimate the curve based on grain size curve, other method obtain the curve from a sample set of functions built into the software, and the other two are close forms equations based on known curve fit parameters (e.g. Fredlund and Xing, 1994; Van Genuchten, 1980). For hydraulic conductivity there is also predicting methods (e.g. Fredlund et al., 1994; Green and Corey, 1997; Van Genuchten, 1980). To model the increase of shear strength due to soil suction there are two possibilities: the use of the parameter $\varnothing \mathrm{b}$ (an angle defining the increase in strength due to the negative pore-water pressure) and the volumetric water content function (SWRC).

The GEO5 software uses the Log-linear, Gardner and Van Genuchten models for flow analysis. Also is possible to establish the ground water table including suction.

Also, in the absence of field measurements of soil suction [15], computer programs such as VSDI, HYDRUS 6.0 or SUTRA can be used to estimate the soil-suction values if the soil-moisture characteristics (SWRC) and hydraulic conductivity are known in detail. Also laboratory measurements of soil shear strength at different suction values can be compared to estimate the shear strength at field conditions.

\section{Discussion and Conclusions}

For geotechnical final design [16] is recommended the use of the direct measurement experiments (triaxial, shear box, oedometer and ring shear for unsaturated soils) and the indirect measurement experiments (SWRC measurement); being the last alternative proposed by the authors of this paper, because it can be introduced in El Salvador more 
quickly and simply. For preliminary geotechnical designs the classification tests (grain-size distribution) and data base mining can be used. Nowadays different geotechnical software like Geoslope, Soilvision and Plaxis are able to run simulations using this kind of information for slope stability and infiltration-evaporation simulations.

For the filter paper (Fig. 5), different equations [25] were used (e. g. ASTM D5298, Chandler et al., 1992 and Oliviera and Marinho, 2006), but if compared with the pressure plate results, the Oliviera and Marinho equations show a better fit. The range of the filter paper test is of $0-10,000$ or greater and compared to the pressure plate was a faster method, additionally is possible to measure total suction. Preliminary results of the models used to describe the SWRC of TBJ, indicate that the filter paper data also has a better coefficient of determination (R2) than the values obtained with the pressure plate.

Comparison (Fig. 5) between the results of different methods (filter paper, pressure plate, tensiometer and suction probe) revealed a good correspondence. The consolidated state and the grain size distribution of TBJ might influence the observed differences in the SWRC results.

Previously there have been some studies about monitoring of slopes in weathered soils [26] to verify design assumptions or for use when checking validity of any analytical and numerical models. According to [15] studies in Brazil revealed that the loss of soil suction during rainstorms (without development of positive pore pressure) can explain failures of shallow soils on steep slopes of residual and alluvial soils. Tensiometer measurements presented a decrease of suction after an intense rainfall. The suction increased with depth below the ground surface.

Currently, field monitoring is starting in Tierra Blanca Joven (TBJ). The use of Quickdraw tensiometers (direct measure of matric suction, Fig. 5) and TMS3 of TOMST (new version, to obtain soil moisture content) could be a good way to build a methodology for an early warning system for the slopes (Fig. 7).

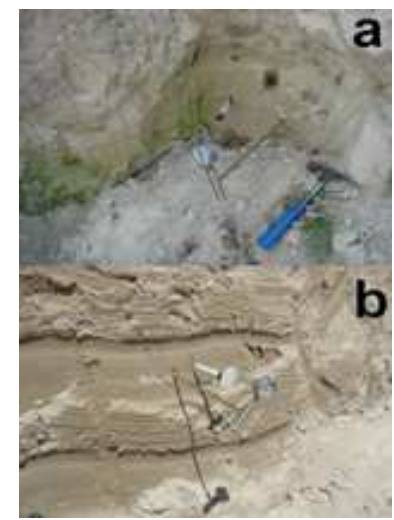

Figure 7. Measurement of soil moisture content in TBJ slope of G unit. a) monitoring point 1 in Fig. 9 (TMS1, left side of photo) and suction (tensiometer, right side of photo). b) photo is point 2 of Fig. 9 in Mejicanos.

The use of tensiometer (an established method) can help to validate the use of TMS into geotechnical monitoring.
The evolution and changes, of suction and water content, experimented in different places of the MASS will help in the understanding of the relation between rain, evaporation, weathering processes and critical soil moisture content of TBJ.

For the TMS device, a calibration curve is needed. Laboratory and field calibration curves are planned for the chosen monitoring places in different units of TBJ. In the preliminary results using TMS1 (January through April of 2013) (Fig. 8 and Fig. 9) is possible to observe some tendency in the results in spite of different conditions in the monitoring places. Soil moisture is (communication of $\mathrm{M}$. Šanda, 2012) based on time domain transmission (TDT) principle for the full range of soil moisture $(50-200 \mathrm{MHz}$ operation range in water to air, respectively) by the TMS (TOMST measuring system) device.

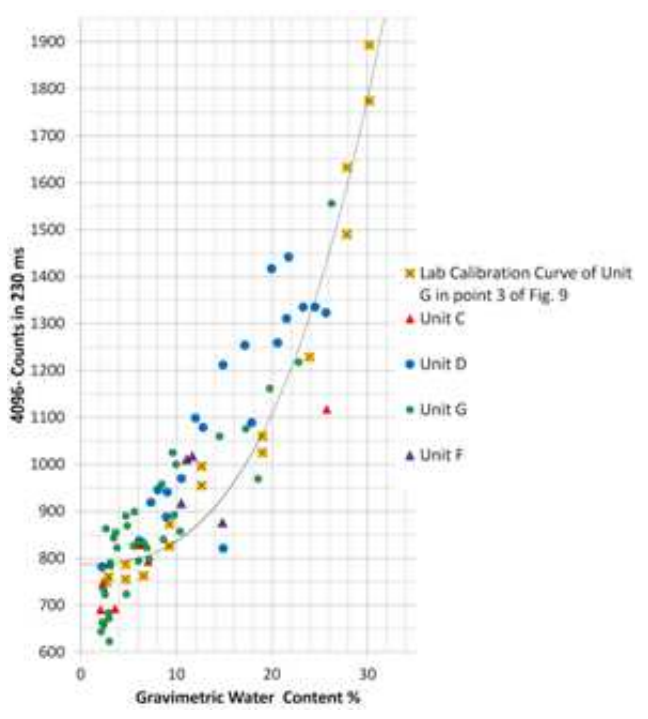

Figure 8. Preliminary results using TMS1 in some units of TBJ in different sectors of the Metropolitan Area of San Salvador (MASS). The calibration curve belongs to point 3 of Fig. $9\left(13^{\circ} 43^{\prime} 5.83^{\prime \prime} N, 89^{\circ} 9^{\prime} 33.24^{\prime \prime} W\right)$, being the same layer used for the filter paper and pressure plate tests.

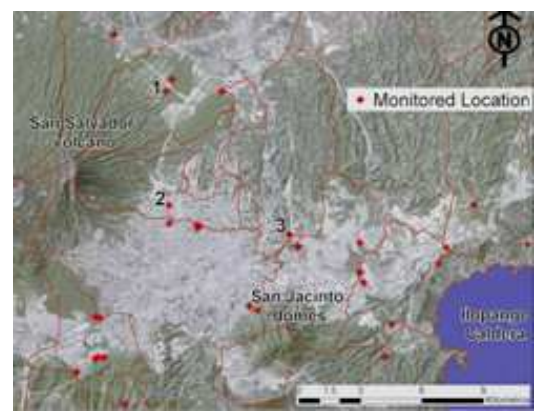

Figure 9. Monitored points using TMS1 and tensiometer in different sectors of the Metropolitan Area of San Salvador (MASS).

TMS also measures temperature at levels $-10,0$ and +12 $\mathrm{cm}$ relative to soil surface when installed vertically; in the preliminary results for TBJ the average temperature difference (when monitored) between surface and inside the slope was of $3.8^{\circ} \mathrm{C}$, this could cause the movement of vapor, water and salts from the soil. The air temperature in the area 
(Communication of MARN, 2013) varied between 17-34 $\mathrm{C}^{\circ}$. Gravimetric water content of monitored TBJ units during the beginning of the dry season revealed elevated capability of retention of water in the $\mathrm{D}$ unit (much fine grain size), and also with the $\mathrm{G}$ unit, some weathering processes (oxidation traces) that can contribute somehow in the problematic of mass movements.

Both probe readings (TMS and tensiometer) are unaffected by different soil types, soil temperatures or salinity conditions. The main limitation of the tensiometer in TBJ is that if the soil is becoming dry ( $>50 \mathrm{kPa})$ the permeability decrease and the drainage is slower, making difficult obtaining a good reading and the data has to be discarded. The practical reading range for the Quickdraw tensiometer is from $0 \mathrm{kPa}$ (saturated) to $77.5 \mathrm{kPa}$ and 74 for elevations (above sea level) of $600 \mathrm{~m}$ and $900 \mathrm{~m}$, respectively (Communication of Soilmoisture, 2012).

For problematic soils [11] is necessary earlier in the project to identify and describe them; estimate the extent and degree of wetting; estimate the collapse strains and collapse settlements; and to explore possible mitigation alternatives.

According to [13] some of the alternatives for improving the behavior of problematic soils are: removal of the sensitive soil to the moisture change, replacement or compaction, avoid saturation of soil, chemical stabilization, controlled saturation, deep dynamic compaction, piles and foundations that can stand differential settlements.

An important aspect to research are the conditions or changes that control the failure or denudation process in the slopes and what is the key aspects in the soil that control them: moisture content, cementation, weathering, evaporation, external activities and also vibrations, this last one is very important because liquefaction $[2,8]$ was observed in TBJ and future testing with the proper equipment is needed. The collapse or slab failure mechanism was first described by [4], but it was not studied in more detail in spite of the problematic that generates in the ravines, rivers and housing projects through all year.

Research of osmotic and total suction is important in TBJ also $[2,4,16]$ because of the presence of salts on the surface of the slopes (the salts are left behind as white deposit after evaporation), this crust of minerals prevent the moisture loss from the slope.

\section{Acknowledgments}

The work has been funded in the framework of cooperation between the Oficina de Planificación del Área Metropolitana de San Salvador (OPAMSS), Czech Technical University in Prague (ČVUT), Universidad de El Salvador (UES), Czech Geological Survey and Ministerio de Medio Ambiente y Recursos Naturales de El Salvador (MARN). Authors acknowledge support of Oficina de Planificación del Área Metropolitana de San Salvador (OPAMSS), TOMST, Agronomy Faculty and Civil Engineer School of Universidad de El Salvador. Special thanks go to Jaroslav Lexa, Walter Hernandez, Jan Schrofel, Jan Valenta, Martin
Šanda, Tomaš Haase, Martin Šimral, Cesar Elias, Edgard Peña, Lesly Mendoza, José Landaverde, Oscar Ayala, Cecy, Andres and Daniel Chávez for assistance during this project.

\section{References}

[1] J. Lexa, J. Šebesta, J. A. Chávez, W. Hernandez and Z.Pécskay, "Geology and volcanic evolution in the southern part of the San Salvador Metropolitan Area", Journal of Geosciences, Vol. 56 pp.105-140, 2011.

[2] J. Chávez, W. Hernandez, L. Kopecky, "Problemática y conocimiento actual de las tefras Tierra Blanca Joven en el Área Metropolitana de San Salvador, El Salvador", Revista Geológica de América Central, Vol. 47,117-132, 2012.

[3] C. Amaya. and E. Hayem,"Introducción al estudio de suelos parcialmente saturados e inicio de la caracterización de la Tierra Blanca del AMSS", Universidad Centroamericana José Simeón Cañas, p. 147, 2000.

[4] W. Hernández, "Características geotécnicas y vulcanológicas de las tefras de Tierra Blanca Joven, de Ilopango, El Salvador", Universidad Politécnica de El Salvador, p. 115, 2004.

[5] R. Rolo, J.J. Bomer, B.F. Houghton, J. W. Vallance, P Berdousis, C. Mavrommati and W. Murphy, "Geologic and engineering characterization of Tierra Blanca pyroclastic ash deposits", Geological Society of America, Special Paper 375, pp. 55-67, 2004.

[6] B. Molina., G. Pérez and M. Vásquez, "Caracterización geotécnica de las tefras Tierra Blanca Joven: unidad "G" en la zona proximal y obras de protección", Universidad Centroamericana José Simeón Cañas, p. 133, 2009.

[7] J. Avalos, and R. Castro, R, "Caracterización geológica y geotécnica de la unidad "G" de Tierra Blanca Joven", Universidad Centroamericana José Simeón Cañas, p. 95, 2010.

[8] J. A. Chávez, J.Schrofel, J. Valenta, J. Šebesta and W. Hernandez, "Engineering geology mapping in southern part of the Metropolitan Area of San Salvador", Revista Geológica de América Central, Vol. 46, pp.161-178, 2012.

[9] M. M. Ali, "Identifying and analyzing problematic soils. Geotechnical and geological engineering", Geotechnical and Geological Engineering. Vol. 29(3), pp.343-350, 2010.

[10] D.G. Fredlund and H. Rahardjo, Soil mechanics for unsaturated soils, 1993, Wiley-Intescience Publications, p. 517.

[11] S. Houston, W. Houston, C. Zapata and C. Lawrence, "Geotechnical engineering practice for collapsible soils" in Unsaturated soil concepts and their application in geotechnical practice, Toll D, Eds. Kluwer Academic Publishers, 2001, pp. 333-355.

[12] C. A. Alvarado, "Modelo conceptual y vulnerabilidad intrínseca del acuífero Quezaltepeque-Nejapa", Universidad de El Salvador, p. 54, 2007.

[13] S. Houston and W. Houston, "Collapsible soil enginnering", in Unsaturated soil engineering practice, Houston S, Fredlund D, Eds. ASCE, New York, 1997, pp. 199-232.

[14] C. Ng, and B. Menzies, Advanced unsaturated soil mechanic and engineering. Taylor and Francis, 2007, p. 687. 
[15] W. Savage, R. Baum, "Instability of steep slopes" in Debris-flow hazards and related phenomena, M. Jakob and $\mathrm{O}$. Hungr, Eds. Praxis Publishing, 2005, pp.53-79.

[16] D. G. Fredlund, H .Rahardjo and M.D. Fredlund, Unsaturated soil mechanics in engineering practice. John Wiley \& Sons, 2012, p. 926.

[17] H. Rahardjo H and E. C. Leong, "Soilwater characteristic curves and flux boundary problems" in Unsaturated soil engineering practice, Houston S, Fredlund D, Eds. ASCE, New York, . 1997, pp. 88-112.

[18] W. S. Sillers, D.G. Fredlund and N. Zakerzadeh, "Mathematical attributes of some soil-water characteristic curve models " in Unsaturated soil concepts and their application in geotechnical practice, Toll D, Eds. Kluwer Academic Publishers, 2001, pp. 243-283.

[19] D. G. Fredlund and A. Xing, "Equations for the soil-water characteristic curve", Can. Geotech. J. Vol. 31, pp. 521-532, 1994.

[20] M.A. Guzmán, and E. Melara, "Propiedades ingenieriles del suelo del área metropolitana de San Salvador, El Salvador", Revista ASIA, Vol. 122, pp. 14-22,1996.
[21] X. Liu, X. Yo, and S. Xu, "A new method to estimate the parameters of van Genuchten retention model using degree of phosphorus saturation (DPS)", African Journal of Agricultural Research. Vol. 6(20), pp.4800-4806, 2011.

[22] K. Seki, "SWRC fit - a nonlinear fitting program with a water retention curve for soils having unimodal and bimodal pore structure", Hydrol. Earth Syst. Sci. Discuss. Vol. 4, pp.407-437, 2007.

[23] D.G. Fredlund, "An introduction to unsaturated soil mechanics" in Unsaturated soil engineering practice, Houston S, Fredlund D, Eds. ASCE, New York, 1997, pp. 1-37.

[24] E. Murray and V. Sivakumar, Unsaturated soils: A fundamental interpretation of soil behavior, Wiley-Blackwell, 2010, p.284.

[25] K. Bicalho, A. Correia, S. Ferreira, J-M. Fleureau and F. Marinho, "Filter paper method of soil suction measurement", Proceedings of XIII Panamerican Conference on Soil Mechanics and Geotechnical Engineering, v. 1. p. 1-6., July 2007.

[26] C. Ng, S. Springman and E. Alonso, "Monitoring the performance of unsaturated soil slopes", Geotechnical and Geological Engineering, Vol. 26 (6), pp.799-816, 2008. 